\title{
PROPAGANDA POLÍTICA Y PODER REAL EN LA CASTILLA TRASTAMARA: UNA PERSPECTIVA DE ANÁLISIS ${ }^{1}$
}

\author{
José MANUEL NiETo SORIA \\ Universidad Complutense de Madrid
}

\begin{abstract}
SUMARIO
1. La "representación" del poder real. 2. La retórica política. 3. La imagen ceremonial. 4. Los símbolos de la realeza. 5. La expresión artística y los escenarios de la monarquía. 6. Los agentes de la propaganda regia.
\end{abstract}

\section{LA "REPRESENTACIÓN" DEL PODER REAL}

Se atribuye a Pascal una sentencia, según la cual, el fundamento más sólido del poder monárquico sería precisamente su representación ${ }^{2}$. Seguramente puede considerarse una interpretación un tanto exagerada de lo que, al menos a fines del Medievo y comienzos de la Modernidad, fueron las monarquías, pero no cabe duda que esa representación del poder

\footnotetext{
1 Este trabajo se encuadra en el Proyecto de Investigación Multidisciplinar titulado Propaganda y legitimación en los orígenes de la Monarquía Hispánica (ca. 1400-ca. 1520): una visión multidisciplinar, financiado por la Universidad Complutense de Madrid.

${ }^{2}$ Peter LEWIS, Pourquoi aurait-on voulu réunir des états généraux, en France, à la fin du Moyen Age, "Représentation, pouvoir et royauté à la fin du Moyen Âge", ed. de Joël Blanchard, París, 1995, p. 123. En cierto modo, la opinión atribuída a Pascal vendría a decir lo mismo que aquella otra de Maquiavelo, según la cual, el hecho de gobernar consistiría ante todo en hacer creer.
}

"Anurio de Estudios Medievales", 25 (1995) 
monárquico, si acaso no fue su fundamento más sólido, sí que supuso una de las facetas de mayor valor sintomático en lo que se refiere a cuáles eran las nuevas pretensiones de la monarquía en tanto que realidad política definida, por lo que el análisis de tal cuestión exige de una valoración específica si se pretende comprender en toda su complejidad la realeza en el contexto de los tiempos tardomedievales 0 , si se prefiere, protomodernos.

A fines de la Edad Media, los colaboradores de los monarcas eran conscientes de la importancia que para el ejercicio del poder regio tenía su puesta en escena, en el más amplio sentido del término, propiciando una imagen apologética de ese poder que pretendía, en unos casos, ofrecer una expresión tangible de sus nuevas conquistas en el plano de la preponderancia política 0 , en otros casos, promover la ficción de una posición muy superior a la que realmente ostentaba en el contexto de las relaciones políticas ${ }^{3}$. Las tendencias observadas en los últimos años por algunos de los enfoques más renovadores dentro de la denominada historia política, han dado reflejo en diversas investigaciones de lo que fue esa consciencia que, con un término contemporáneo, podemos calificar, de propagandística, lo que permite hablar de la propaganda política como tema historiográfico claramente reconocible para la época considerada ${ }^{4}$.

El concepto clave desde el que cabe entender a fines del medievo la utilización de la propaganda como procedimiento político es el de representación. Sobre el valor interpretativo de dicho concepto han llamado la atención en los últimos años diversos autores ${ }^{5}$. Desde la perspectiva de análisis que ofrece la idea de representación puede comprenderse cómo, en definitiva, algo puede significar otra cosa distinta de lo que es en sí misma, de modo que un símbolo puede suponer la representación de una atribución o de una

\footnotetext{
${ }^{3}$ Sobre esta "consciencia propagandística" puede recordarse la actitud de Fernando del Pulgar con relación a Isabel la Católica a la que, ante las acusaciones de excesivo boato, le recomendará que "ninguna cerimonia en esta vida se puede facer tan por extremo a los reyes, que mucho mas no requiera el estado real; el qual ansi como es uno e superior en los Reynos, ansi debe mucho estremarse, e resplandecer sobre todos los otros estados, pues tiene autoridad divina en la tierra". Fernando del PULGaR, Claros varones de Castilla, edición de Jesús Domínguez Bordona, Madrid, 1969, p. 152.

${ }^{4}$ Un conjunto de trabajos en el que se aborda en una perspectiva histórica esa relación entre política y propaganda en Myriam YARDENI (ed.), Idéologie et propagande en France, París, 1987.

${ }^{5}$ Véase al respecto: Carlo GinzBURG, Représentation: le mot, l'idée, la chose, "Annales. Economies. Sociétés. Civilisations", 46 (1991), 1.219-1.234 y Roger CHARTIER, Le monde comme représentation, "Annales. Economies. Sociétés. Civilisations", 44 (1989), 1.505-1.520.
} 
forma de ejercer el poder, o una ceremonia, la plasmación de un compromiso o de un consenso, o la imagen de un rey comportar la representación global de la comunidad política que rige. Es así que todas las expresiones de lo que a fines del medievo fueron formas de propaganda, en último término, lo que significan es la consciencia que, de hecho, se tuvo de que mediante el recurso a la representación, fuera de índole retórica, ceremonial, simbólica o iconográfica, era posible hacer más perceptibles la presencia y las atribuciones de un poder, en este caso el real, así como inclinar a la solidaridad en torno a sus pretensiones.

Planteada así la cuestión, no es de extrañar que el estudio de las diversas formas de propaganda política, sobre todo aquéllas que se expresaban en torno al poder regio, hayan concitado en los últimos años, tanto dentro de la historiografía occidental, en general, como de la española, en particular, un amplio interés entre los investigadores en el contexto de una redefinición de lo que, sobre todo a partir de comienzos de los años ochenta, comenzó a entenderse como nueva historia política, en tanto que forma de entender lo político desde perspectivas temáticas, metodológicas e interpretativas innovadoras ${ }^{6}$.

El periodo bajomedieval en su conjunto, en cuanto que, tal como ha señalado Antony Black ${ }^{7}$, época trascendental para los valores políticos del mundo moderno, al llevar a cabo un importante proceso de transformación e innnovación de principios políticos, constituye terreno abonado para la investigación de los problemas que giran en torno a las formas de propaganda política. En una época de intensa transformación de las estructuras políticas, en donde las crisis de legitimidad son inevitables, factores como la legitimación ideológica y la opinión pública están llamados a tener un protagonismo muy importante ${ }^{8}$. No es por ello de extrañar que una de las manifestaciones más características de la propaganda política, como lo es la actividad ceremonial, alcance particular relieve, al convertirse en un medio de sintetización y de exteriorización de argumentaciones jurídicas traducidas

${ }^{6}$ Referencia metodológica obligada en tanto que trabajo pionero en la redefínición de la historia política en el que se sintetizan las pautas de investigación a tener en cuenta es el artículo de W.P. BlOCKMANS, La nouvelle histoire politique, en "L'histoire et ses méthodes", Lille, 1981, 109-121.

'Antony BLACK, El pensamiento político en Europa, 1250-1450, Cambridge, 1996, p. IX.

${ }^{8}$ Sobre ello, aludiendo al problema de la génesis del Estado Moderno, ha llamado la atención Jean Phillipe GENET, L'État Moderne: un modèle opératoire?, en "L'État Moderne: genèse", París, 1990, 269-270. 
en mucho casos a expresión litúrgica, en parte, como consecuencia del papel ideológico que sigue jugando la teología política9 a pesar de los indicios de secularización bajomedieval.

Suele constituir una tendencia general en todo el Occidente durante los últimos siglos medievales el que la relación entre el rey y los súbditos se vaya transformando en algo cada vez más impersonal. La burocratización de las funciones administrativas y la progresiva sedentarización de las distintas cortes produce un efecto inevitable de alejamiento entre el rey y los súbdtos, haciéndose, por ello, particularmente necesario recurrir a fórmulas y signos de representación que aseguren una cierta forma de omnipresencia regia y, a la vez, se favorezca el sentimiento de pertenencia a una comunidad política, cuestiones ambas en las que los recursos propagandísticos tienen un papel decisivo ${ }^{10}$.

La propaganda política tuvo a fines del medievo unas fórmulas de manifestación bien definidas y entre las que, habitualmente, se produjo una estrecha relación de complementariedad, contribuyendo así a potenciar o completar una determinada fórmula la imagen que se proyectaba con otra distinta, propiciándose una imagen global. Así se puede hablar de recursos retóricos, simbólicos, ceremoniales e iconográficos o artísticos.

También para Castilla y, en particular, para la época trastámara, se puede constatar la presencia de los problemas generales ya enunciados, así como la utilización de los recursos propagandísticos que se acaban de enumerar. Del mismo modo, la influencia de nuevos planteamientos en la forma de abordar los problemas históricos de índole política ha contribuído a que, en los últimos años, asuntos, como el de la propaganda política, que tradicionalmente apenas habían tenido presencia en la historiografía española de ámbito medieval, estén comenzando a contar ya con un número apreciable de publicaciones, por lo que puede ser oportuno afrontar un intento de sistematización temática de esas aportaciones y de valoración en orden a la apertura de nuevas perspectivas de investigación. Este es el objetivo que me propongo para las próximas páginas, abordando primero las aportaciones que

\footnotetext{
${ }^{9}$ Véase al respecto el artículo de Alain BoUREAU, Les cérémonies royales françaises entre perfomance juridique et compétence liturgique, "Annales. Economies. Sociétés. Civilisations", 46 (1991), 1.253-1.264.

${ }^{10}$ El problema de la necesidad de encontrar formas de representación regia en el contexto de las transformaciones políticas de fines del medievo ha sido abordado desde una amplia diversidad de puntos de vista en Joël BLANCHARD (ed.), Représentation, pouvoir et royauté à la fin du Moyen Âge, París, 1995.
} 
han tenido lugar con relación a cada uno de los recursos propagandísticos ya mencionados, así como las referentes a un problema de gran importancia dentro de la perspectiva elegida, como es el de los agentes de la propaganda regia, para tratar de establecer, finalmente, unas observaciones sobre las expectivas de futuro de la propaganda política en la Castilla Trastámara en tanto que problema historiográfico.

\section{LA RETÓRICA POLÍTICA}

El conjunto de la época bajomedieval supone para Castilla, como para otros reinos occidentales, un periodo de intensa actividad de creación o difusión de formulaciones políticas que se producen en niveles de reflexión muy distintos, que van desde el popular (refranero)" hasta el académico, pasando, entre otros, por el cronístico o el literario. Ello hace que el estudio de la ideología política en la Castilla bajomedieval y, en particular, durante el periodo trastámara ofrezca amplias posibilidades, en tanto que objeto de investigación ${ }^{12}$, aunque no exento de dificultades desde el punto de vista de las cautelas metodológicas ${ }^{13}$.

La investigación sobre la ideología política en la Castilla trastámara partía de una base muy apreciable en cuanto a la disponibilidad de un conjunto de obras de síntesis que facilitaban extraordinariamente la aproximación al tema ya en un nivel mås monográfico. Junto con una sistematización de aquellos autores que pueden considerarse como pensadores políticos fundamentales del periodo $^{14}$, se han producido esfuerzos de

\footnotetext{
"Louis COMBET, Recherches sur le 'Refranero' castillan, París, 1971 y Eleanor O'KANE, Refranes y frases proverbiales españolas de la Edad Media, Madrid, 1959.

${ }^{12}$ Un panorama de conjunto de las publicaciones referidas a la ideología política en la España bajomedieval puede verse en: José Manuel NIETO SORIA, La ideología política bajomedieval en la historiografía española, "Hispania", 175 (1990), 667-681.

${ }^{13}$ Sobre esas dificultades metodológicas, pensando sobre todo, aunque no exclusivamente, en el caso de la monarquía trastámara, puede verse: José Manuel NIETO SORIA, Ideología y centralización política en la crisis bajomedieval. Vías de aproximación y dificultades interpretativas, "Historia a debate. Medieval", edic. de Carlos Barros, Santiago de Compostela, 1995, pp. 151-164.

${ }^{14}$ Juan BENEYTO PÉREZ, Los orígenes de la ciencia política en España, Madrid, 1949. Más recientemente, también con la perspectiva de stablecer una especie de hilo conductor entre los autores políticos más relevantes, se ha publicado el libro de Francisco ELÍAS DE TEJADA Y SPínOla, Historia de la literatura política en las Españas, 3 vols., Salamanca, 1991.
} 
incardinación de los cambios ideológicos en el contexto de transformación político-social, sobre todo para lo que se refiere al siglo $X^{15}$, así como la profundización, a partir cle fuentes de diversa índole, en las distintas imágenes aplicadas a la descripción del rey y del poder regio ${ }^{16}$, quedando éstas clasificadas a partir de la distinción entre lo que serían imágenes de fundamentación esencialmente teológica, frente a otras de índole jurídica ${ }^{17}$, siendo lo teológico y lo jurídico el marco natural de desarrollo, teniendo en cuenta las tendencias intelectuales de la época en lo que afectan a cualquier forma de elucubración política. Manifestación de este volumen de investigaciones ha sido el que se vaya observando en las aproximaciones de conjunto a la dimensión política de la Castilla trastámara la incorporación de aquellas cuestiones que afectan a la ideología política en sus distintas manifestaciones retóricas como un factor más de explicación ${ }^{18}$.

La sustentación ideológica del poder regio tuvo, de manera general para las distintas monarquías occidentales, y también para la realeza trastámara, una serie de puntos de referencia obligados en distintos conceptos clave que formaron parte de la reflexión jurídica, filosófica y teológica que tenía como objeto el establecimiento de un modelo de monarquía ideal. La concepción corporativa, tan querida de la escolástica y del tomismo y que aseguraba la representación orgánica del reino y de las relaciones que se establecían entre éste y el monarca, mantuvo plena vigencia en la ideología política castellana ${ }^{19}$.

Pocos conceptos estarían llamados a tener tanto éxito en el mundo de las ideas políticas como el de soberanía. Su presencia, aunque con significados no siempre idénticos, pero cada vez con más frecuencia referida a la posición de superioridad que el poder del rey ostenta en su reino, cabe

\footnotetext{
${ }^{15}$ José Antonio MARAVALL, Estado moderno y mentalidad social. Siglos XV a XVII, 2 vols., Madrid, 1972.

${ }^{16}$ José Luis BeRMEjo CABERO, Máximas, principios y símbolos políticos (una aproximación histórica), Madrid, 1986, del mismo autor, Derecho y pensamiento político en la literatura española, Madrid, 1980 y Amor y temor al rey. Evolución histórica de un tópico político, "Revista de Estudios Políticos", 1973, pp. 107-127.

17 José Manuel NIETO SORIA, Fundamentos ideológicos del poder real en Castilla. Siglos XIII al XVI, Madrid, 1988.

${ }^{18}$ A modo de ejemplo reciente de incorporación del discurso ideológico al análisis de los problemas políticos: Luis SUÁREZ FERNÁNDEZ, Monarquía hispana y revolución trastámara, Madrid, 1994.

19 José Antonio Maravall, La idea de cuerpo místico en España antes de Erasmo, "Estudios de historia del pensamiento español", I, Madrid, 1973, pp. 191-214.
} 
detectarla en los textos castellanos desde fines del siglo XIV y, a partir de entonces, seguir la pista a la utilización de tal concepto constituye una referencia obligada en la investigación de la evolución ideológico-política en el tránsito a la modernidad ${ }^{20}$. El relieve que la soberanía alcanza en tanto que concepto político sintomático de la evolución que va experimentando el ejercicio del poder regio, probablemente, sólo sea comparable con el que cabe apreciar para otro concepto de enorme trascendencia para el futuro como es el de bien común ${ }^{21}$. Es este un concepto que, al igual que sucede con el de soberanía, se ve sometido a interpretaciones múltiples que, en este caso, van desde la justificación de las formas más ilimitadas de autoritarismo regio hasta, por el contrario, la argumentación en favor de medios de control que aseguren la fiscalización sistemática del poder real. La idea de corona, en tanto que concepto político, forma parte, junto con el ya aludido bien común, de lo que he definido en alguna ocasión como conceptos transpersonalizadores, en tanto que, según la interpretación que de ellos se haga, se puede abrir la posibilidad de diferenciar de forma precisa la persona del rey respecto del ejercicio concreto del poder regio ${ }^{22}$.

Desde esta perspectiva de los conceptos jurídico-políticos, resulta esencial la definición de la posición del rey con respecto a la ley. Es esta una cuestión que resulta de lo más delicada y resbaladiza, si se tiene en cuenta que, junto a declaraciones de sometimiento del rey a la ley, no se deja de aprovechar la ocasión, bien por la vía de fórmulas como poderio real absoluto, o también, de cierta ciencia e motu proprio -utilizadas no sólo en Castilla $^{23}$-, para establecer referencias justificadoras a la hora de adoptar el monarca una decisión que, de hecho, supone una innovación legal, cuando no, simplemente, una contravención con respecto a normas preexistentes. Se trata, por tanto, de un problema que bien merece algunas investigaciones

${ }^{20}$ José Luis BERMEJO CABRERO, Origenes medievales de la idea de soberanía, "Revista de Estudios Políticos", 200-201 (1975), pp. 283-290.

${ }^{21}$ Reflexiones genéricas de interés sobre este concepto en Pierangelo SCHIERA, Le bien commun et le principe d'association dans l'héritage doctrinale de l'État Moderne, "The Heritage of the Pre-Industrial European Staten , edición de W.P. Blockmans, J. Borges de Macedo y J.Ph. Genet, Lisboa, 1996, pp. 185-195.

22 José Manuel NIETo SORIA, La transpersonalización del poder regio en la Castilla bajomedieval, "Anuario de Estudios Medievales", 17 (1987), pp. 559-570.

${ }^{23}$ Para su utilización por la monarquía francesa puede verse: Jacques KRYNEN, 'De nostre certaine science'... Remarques sur l'absolutisme législatif de la monarchie médiévale française, "Renaissance du pouvoir législatif et genèse de l'Etat", edición de A. Gouron y A. Rigaudière, Montpellier, 1988, pp. 131-144. 
monográficas en las que se ponga en relación el estudio de procedimientos institucionales concretos con enunciaciones de principios con carga ideológica relevante ${ }^{24}$. Con relación a esta cuestión, recientemente, aunque desde una perspectiva más de historia intelectual que de historia institucional y política, se ha puesto de relieve la valoración por algunos colaboradores reales, en concreto, Alfonso de Cartagena, obispo de Burgos, oidor y consejero de Juan II, del concepto jurídico de epiqueya, por el que se reconocía al monarca la facultad de emitir sentencias contrarias a la norma en aplicación de criterios de generosidad hacia el reo, como virtud propia de la condición real ${ }^{25}$.

Desde otra perspectiva bien distinta, la presentación de la figura regia como poseedora de una marcada dimensión mesiánica fue un recurso ampliamente empleado como elemento de propaganda ${ }^{26}$, sobre todo, en el contexto del reinado de los Reyes Católicos ${ }^{27}$. Muy directamente relacionada con ello, la utilización propagandística de textos de carácter profético sobre los reyes y la realeza fue un fenómeno relativamente común a fines del medievo en Occidente ${ }^{28}$ y que recientemente ha vuelto a ofrecer especial

\footnotetext{
${ }^{24}$ Desde esta perspectiva, puede servir como ejemplo de referencia: Salustiano de DIOS, Gracia, merced y patronazgo real. La Cámara de Castilla entre 1474-1530, Madrid, 1993.

${ }^{25}$ Luis FERnÁndez GAllardo, Cultura jurídica, renacer de la Antigüedad e ideologia política. A propósito de un fragmento inédito de Alonso de Cartagena, "En la España Medieval", 16 (1993), pp. 119-134.

${ }^{26}$ El problema del mesianismo en el contexto de la baja Edad Media hispánica ya quedó planteado por Américo CASTRO, Aspectos del vivir hispánico. Espiritualismo, mesianismo, actitud personal en los siglos XIV al XVI, Santiago de Chile, 1949.

${ }^{27}$ En esta línea de trabajo fueron pioneras las investigaciones de Alain MiLHOU, Colón y su mentalidad mesiánica en el ambiente franciscanista español, Valladolid, 1983; La chauve souris, le Nouveau David et le Roi Caché (trois images de l'empereur des derniers temps dans le monde ibérique: XIIle-XVIIe siècles, "Mélanges de la Casa de Velázquez", XVIII-1 (1982), pp. 61-78 y Propaganda mesiánica y opinión pública. Las reacciones de las ciudades del reino de Castilla frente al proyecto fernandino de cruzada (1510-1511), "Homenaje a José Antonio Maravall", III, Madrid, 1985, pp. 51-62.

${ }^{28}$ Colette BEAUNE y André VAUCHEZ, La parole inspirée (visions, révélations, prophéties) et le développement des pouvoirs informels, Roma, 1986. Sobre el mismo tema, también: Fin du monde et signes des tempos. Vision et prophètes en France méridionale (fin XIIle-début XVe siècle), "Cahiers de Fanjeaux, 18 (1992), puede verse en especial, con relación al uso de profecías políticas, los trabajos de M. Aurell y C. Beaune allí contenidos.
} 
interés para algunos historiadores ${ }^{29}$, tando desde el enfoque filológico como histórico ${ }^{30}$.

En los últimos años se viene produciendo un uso cada vez más frecuente del concepto de discurso político como forma de aludir a la estructura retórica que presentan determinadas creaciones, sean textuales, simbólicas, ceremoniales o iconográficas, mediante las que se exaltaban y justificaban interesadamente determinados valores $o$ pretensiones de significado político ${ }^{31}$. Tal planteamiento, haciendo uso o no del propio concepto de discurso político, resulta particularmente aplicable al caso de la producción cronística e historiográfica ${ }^{32}$, en general, muy abundante en la Castilla trastámara y con grandes posibilidades desde la óptica de interpretación ideológico-política ${ }^{33}$, no debiéndose olvidar, además, que, tal como ha hecho observar algún autor, el número de textos de esta índole que se conserva en la Castilla trastámara es pequeño en relación con el que realmente debió de existir ${ }^{34}$.

${ }^{29}$ Ya había sido objeto de atención este asunto por parte de Joaquín GIMENO CASALDUERO, La profecía medieval en la literatura castellana y su relación con las corrientes proféticas europeas, "Estructura y diseño en la literatura castellana medieval", Madrid, 1975, 103-141. 1996.

30 José Guadalajara Medina, Las profecías del anticristo en la Edad Media, Madrid,

${ }^{31}$ Manifestación reciente de ello en: Nilda GUgLIELMI y Adeline RucQuol (coords.), El discurso político en la Edad Media, Buenos Aires, 1995.

${ }^{32}$ Un ejemplo de aplicación del concepto de discurso político a un texto cronístico a fin de destacar los rasgos más sobresalientes de la imagen regia y las argumentaciones sobre las que se fundamenta la justificación de las distintas actitudes políticas que se van sucediendo en Raquel HomeT, El discurso político de Pedro el Cermonioso, "El discurso político en la Edad Media", 97-115. Concluye la autora, tras el análisis de la obra que ha sido objeto de su investigación, en este caso, la crónica del rey de Aragón Pedro el Ceremonioso, cómo a lo largo del discurso se enuncian, junto con la justificación de los hechos -y, precisamente, para explicarlos- las premisas que fundamentaban la monarquía, que no se ofrecen en forma abstracta, sino que emergen del modelo en que el rey se convirtió a si mismo (p. 114). Un análisis propagandístico de textos historiográficos en A. GRANDSEN, Propaganda in English Medieval Historiography, "Journal of Medieval History", 1 (1975), pp. 363-381.

${ }^{33}$ Un ejemplo desde esta óptica de la obra historiográfica del siglo XV en Castilla en: Helen NADER, Los Mendoza y el Renacimiento español, Guadalajara, 1986, pp. 39-55.

${ }^{34}$ Alan D. DEYERMOND, La historiografta trastamara: ¿una cuarentena de obras perdidas?, "Estudios en homenaje a Don Claudio Sánchez Albornoz en sus 90 años", IV, Buenos Aires, 1986, pp. 161-193. 
Junto con algunos estados de la cuestión ${ }^{35}$ y algunas investigaciones monográficas sobre determinados textos cronísticos e historiográficos relevantes del siglo $\mathrm{XV}^{36}$, autores como Pedro López de Ayala ${ }^{37}$, Rodrigo Sánchez de Arévalo, Pablo y Alfonso de Santa María ${ }^{38}$, Diego Enríquez del Castillo $^{39}$ o Alfonso de Palencia ${ }^{40}$ han sido objeto de particular atención como consecuencia del importante trasfondo ideológico-político que se detecta en la narración de cada uno de ellos, en donde el compromiso político sale a cada paso, lo que obliga a forzar el sentido del discurso para favorecer la causa de la que el autor forma parte. Del mismo modo, ya específicamente para la época de los Reyes Católicos, junto a la comprobación hace décadas de un rasgo básico que caracterizaba la producción cronística del reinado, como era el providencialismo ${ }^{41}$, en los últimos años se ha ampliado muy considerablemente tanto la disponibilidad de textos

${ }^{35}$ Ludwig VONES, Historiographie et politique: l'historiographie castillane aux abords du XIVe siècle, "L'historiographie castillane aux abords du XIVe siècle", edic. de J. Ph. Genet, París, 1991, pp. 177-188.

${ }^{36}$ Robert B. TATE, Ensayos sobre la historiografía peninsular del siglo XV, Madrid, 1970.

${ }^{37}$ José Luis Martín Rodríguez, Defensa y justificación de la dinastía Trastámara. Las crónicas de Pedro López de Ayala, "Espacio, Tiempo y Forma", serie III (Historia Medieval), 3 (1990), pp. 157-180.

${ }^{38}$ Sobre Rodrigo Sánchez de Arévalo y los Santa María son referencias obligadas los trabajos monográficos que a estos personajes dedica Robert B. Tate en su Ensayos... Sobre Pablo de Santa María, también puede verse: Alan D. DEYERMOND, Historia universal e ideología nacional en Pablo de Santa María, "Homenaje a Alvaro Galmés de Fuentes", II, Oviedo-Madrid, pp. 313-324. Sobre Alfonso de Cartagena, puede verse el repertorio bibliografico recogido en María MORRÁS, Latinismo y literalidad en el origen del clasicismo vernáculo: las ideas de Alfonso de Cartagena (ca. 1384-1456), "La traducción en España, ss. XIV-XVI", edic. de Roxana Recio, León, 1995, pp. 35-58. Un estudio reciente en profundidad sobre una las principales iniciativas propagandísticas de Alonso de Cartagena al servicio de la realeza castellana: Luis FERNÁNDEZ GALLARDO, Alonso de Cartagena en Basilea (nuevas observaciones sobre el conflicto anglo-castellano), "Archivos Leoneses", $95-96$ (1994), 9-91.

${ }^{39}$ José Luis Bermejo CABrero, Las ideas políticas de Enríquez del Castillo, "Revista de la Universidad Complutense de Madrid", 86 (1973), 61-78. Nuevos enfoques sobre la crónica de Enríquez en Aureliano Sánchez Martín, Crónica de Enrique IV de Diego Enríquez del Castillo, Valladolid, 1994.

${ }^{40}$ Robert B. TATE, Alonso de Palencia y los preceptos de la historiografia, "Nebrija y la introducción del renacimiento en España", Salamanca, 1983, pp. 37-51. Antonio ANTELO IGLESIAS, Alfonso de Palencia: historiografia y humanismo en la Castilla del siglo XV, "Espacio, Tiempo y Forma", 3 (1990), pp. 21-40.

"José CEPEDA ADÁn, El providencialismo en los cronistas de los Reyes Católicos, "Arbor", XVII (1950), pp. 177-190. 
historiográficos, como el panorama interpretativo a aplicar sobre los mismos $^{42}$.

Del mismo modo que los textos cronísticos suelen aportar un buen volumen de material en orden a la profundización en problemas ideológicopolíticos, otro tanto se puede decir con relación a una variada diversidad de textos literarios ${ }^{43}$. Los cancioneros reúnen por lo común contenidos muy valorables desde la perspectiva de la apología y exaltación del poder y de la persona real, como desde el ángulo de la descalificación de los enemigos políticos $^{44}$. Del mismo modo, las alegorías literarias ofrecen amplias posibilidades de interpretación política ${ }^{45}$. Recientemente, se ha llamado la atención sobre las posibilidades propagandísticas de los tópicos cruzadistas en la literatura caballeresca hispánica en el tránsito del siglo XV al XVI, debiéndose, además, tener en cuenta la importante presencia de los libros de caballería en las bibliotecas reales y nobiliarias de la época ${ }^{46}$. Un tipo de texto particular que, sin poderse considerar como específicamente literario, sí puede tener ocasionalmente un valor literario y que suele entrar de lleno en la consideración de problemas políticos, pudiendo pretender determinados fines propagandísticos, es el representado por los espejos de príncipes, habiendo sido objeto, hasta el momento, de una muy limitada utilización desde la perspectiva aquí considerada ${ }^{47}$. Una fuente sobre la que merecería la pena llevar a cabo un acercamiento prospectivo desde el enfoque de lo propagandístico sería el sermón con intencionalidad política, tal como ya ha

\footnotetext{
${ }^{42}$ Pedro M. CÁTEdRa, La historiografía en verso en la época de los Reyes Católicos. Juan Barba y su 'Consolatoria de Castilla', Salamanca, 1989.

${ }^{43}$ Alan DEYERMOND, La ideología del Estado moderno en la literatura española del siglo $X V$, "Realidad e imagen del poder. España a fines de la Edad Media", edic. de A. Rucquoi, Valladolid, 1988, pp. 171-193.

${ }^{44}$ José Manuel NIETO SORIA, Apología y propaganda de la realeza en los cancioneros castellanos del siglo XV. Diseño literario de un modelo político, "En la España Medieval", 11 (1988), pp. 185-223.

${ }^{45}$ Robert B. TATE, Political Allegory in Fifteenth-Century Spain: A Study of the 'Batalla campal de los perros contra los lobos' by Alfonso de Palencia (1432-1492), "Journal of Hispanic Philology", I (1979), pp. 169-186.

${ }^{46}$ María del Carmen MARín Pina, La ideología del poder y el espiritu de cruzada en la narrativa caballeresca del reinado fernandino, "Fernando II de Aragón, el rey católico", Zaragoza, 1996, pp. 87-108.

${ }^{47}$ Bonifacio PALACIOS MARTín, El mundo de las ideas políticas en los tratados doctrinales españoles: los 'espejos de príncipes' (1250-1350. "Europa en los umbrales de la crisis (12501350)" (XXI Semana de Estudios Medievales de Estella), Pamplona, 1995, pp. 463-483.
} 
sucedido para algún texto de este tipo en el caso del reino de Aragón $\mathrm{n}^{48}$. A todo ello hay que añadir la presencia de fuentes, en cierta medida literarias, que se producen excepcionalmente con carácter muy ocasional. En este sentido hay que destacar, como un caso muy particular, el de los carteles de batalla que preceden a ciertos duelos, tal como el que se anunció en 1475 entre Alfonso $\mathrm{V}$ de Aragón y Fernando el Católico, muy cargado de propaganda política en sus contenidos ${ }^{49}$.

Es en los contextos históricos en que tiene lugar un proceso de crisis de legitimidad donde el recurso a la propaganda, sobre todo a aquel tipo de propaganda que puede producir una respuesta más inmediata, se constata de un modo particularmente intenso y evidente. El conjunto de la época trastámara es muy rica en la presencia de esos contextos de crisis de legitimidad, pues, junto con lo que fueron los distintos momentos de confrontación, incluso bélica, desde la propia guerra civil que llevó a la entronización de la dinastía, hasta las diversas confrontaciones posteriores, sobre todo en el trascurso del siglo XV, que afectaron especialmente a las relaciones entre la monarquía y una parte relevante de la alta nobleza, hay que llamar la atención sobre lo que podría considerarse como una crisis de legitimidad de presencia más continuada que podría, de hecho, definirse como de carácter estructural. Me refiero a las nuevas pretensiones de autoritarismo regio expresadas repetidamente por la monarquía, que suponían, en la práctica, la exigencia de esfuerzos propagandísticos suplementarios a la hora de dar justificación a lo que eran atribuciones que, siendo, en realidad, innovaciones, se presentaban como innatas a la condición regia o como supuestamente avaladas por una dilatada práctica histórica.

La guerra civil que condujo a la entronización de Enrique II, a la vez que supuso un momento máximo de confrontación de legitimidades, se caracterizó por conllevar un extraordinario despliegue propagandístico, siendo particularmente comprobable para la facción enriqueña ${ }^{50}$. Los textos

\footnotetext{
${ }^{43}$ Pedro María CÁTEDRA, Acerca del sermón político en la España medieval la propósito del discurso de Martín el Humano en las contes de Zaragoza de 1398, "Boletín de la Real Academia de Buenas Letras de Barcelona", 40 (1985-1986), pp. 17-47.

49 José Angel SESMA MUÑoz, Carteles de batalla cruzados entre Alfonso V de Portugal y Fermando V de Castilla (1475), "Revista Portuguesa de História, XVI (1978), pp. 277-295.

${ }^{50}$ Emilio Mitre FERnández, Crisis y 'legitimaciones' dinásticas en la península a fines del siglo XIV, "Bandos y querellas dinásticas en España al final de la Edad Media", [Cuadernos de la Biblioteca Española], 1 (París, 1991), pp. 37-58.
} 
cronísticos se vieron afectados de lleno por el impacto del enfrentamiento, convirtiéndose en una expresión muy relevante de la voluntad propagandística que caracterizó el conflicto ${ }^{51}$. Del mismo modo, la documentación emanada de las cancillerías, sobre todo de la enriqueña, se manejó como un medio de difusión muy activo de aquellos tópicos y lugares comunes mediante los que se pretendía justificar ideológicamente la legitimidad de las aspiraciones trastamaristas, de modo que el conflicto tuvo como un rasgo relevante la presencia de un importante trasfondo ideológico ${ }^{52}$. Tal circunstancia tuvo consecuencias para el futuro, pues ese despliegue propagandístico, manifestado a través de la utilización de diversas fórmulas destinadas a justificar, ya no sólo la legitimidad dinástica, sino también el ejercicio de un poder con amplias pretensiones autoritarias, fundado tanto en referencias de origen jurídico, como teológico, pervivió en las las décadas siguientes, pasando a constituir señas de identidad del aparato ideológico de que hizo gala el conjunto de la dinastía trastamarista ${ }^{53}$.

Si la guerra civil entre Pedro I y Enrique II fue una manifestación particularmente notable de esfuerzo propagandístico mediante el recurso a la más variada retórica política, no puede decirse que constituyese un caso excepcional. Muchas de las fórmulas de exaltación regia que desgrana Enríquez del Castillo en su crónica, parecen cocerse al calor del enfrentamietno entre Enrique IV y la nobleza rebelde ${ }^{54}$. Algunos de los recursos retóricos entonces puestos en juego se podrán constatar de nuevo en el

\footnotetext{
${ }^{51}$ Emilio MITRE FERNÁNDEZ, La historiografía bajomedieval ante la revolución trastámara: propaganda política y moralismo, "Estudios de Historia Medieval en homenaje a Luis Suárez Fernández", Valladolid, 1991, pp. 333-347. José Luis MarTín Rodríguez, Defensa y justificación de la dinastía Trastámara. Las crónicas de Pedro López de Ayala, "Espacio, Tiempo y Forma. Historia Medieval", serie III, 3 (1990), pp. 157-180.

52 Julio VALDEÓN BARUQUE, La propaganda ideológica, arma de combate de Enrique de Trastámara (1366-1369), "Historia. Instituciones. Documentos", 19 (1992), pp. 459-467; María Isabel OSTOLAZA ELIZONDO, La cancillería como arma política en la lucha por el trono: algunos ejemplos de la guerra civil entre Pedro I y Enrique de Trastámara. "Strenae Emmanuelae Marrero Oblatae", La Laguna, 1993, pp. 201-207, y María del Pilar RÁBADE OBRADO, Simbologia y propaganda política en los formularios cancillerescos de Enrique II de Castilla, "En la España Medieval", 18 (1995), pp. 223-239.

${ }^{53}$ Luis SUAREZ Fernández, Monarquía hispana y revolución trastámara, Madrid, 1994, pp. 99-128.

54 José Luis Bermejo CABrero, Las ideas políticas de Enriquez del Castillo, "Revista de la Universidad Complutense de Madrid", 86 (1973), pp. 61-78.
} 
conflicto de las Comunidades de Castilla ${ }^{55}$. La intervención castellanoportuguesa en la guerra civil catalana en 1464 estará convenientemente preparada en lo ideológico con encargos expresos de textos que respalden literariamente los objetivos políticos que se pretendían ${ }^{56}$. Incluso formas rudimentarias de propaganda, basadas en gritos elementales de convocatoria, mediante los que se hacía referencia a una supuesta legitimación regia, se podrán observar en movimientos populares, como el caso de los hermandiños gallegos ${ }^{57}$.

Por lo general, cuando se habla de retórica propagandística relativa al poder real para fines del medievo, se piensa en aquella que tenía como objetivo la exaltación o apología de un poder regio de rasgos cada vez más autoritarios. Es comprensible que sea así, si se tiene en cuenta el predominio de referencias textuales de tal índole. Tal circunstancia no debe ocultar la presencia de lo que podría considerarse como ciertas corrientes de oposición que tratan de plantear alternativas desde el punto de vista del diseño de un modelo político ${ }^{58}$. Esas corrientes de pensamiento opuestas a una solución de monarquía autoritaria, sin poner, por lo general, en cuestión el sistema monárquico, sí tendieron a darle una cierta dimensión "democrática"59, generalmente caracterizada por el mayor protagonismo político de las clases medias, para las que se reivindicaba mayor influencia política ${ }^{60}$ y concediendo particular importancia a conceptos con virtualidad democratizadora 196.

59 José Manuel NIETo SORIA, Fundamentos ideológicos del poder real en Castilla, pp. 167 -

${ }^{56}$ Luis Adao FONSECA, Una elegía inédita sobre la familia de Avís. Un aspecto de la propaganda políica en la Península Ibérica a mediados del siglo XV. "Anuario de Estudios Medievales", 16 (1986), 449-464. Este texto elegíaco de Alonso de Córdoba que justificaba la intervención castellano-portuguesa en Cataluña fue editado por Pedro María CáTEDRA, Alonso de Córdoba, 'Conmemoraçión breve de los Reyes de Portugal', [Biblioteca Humanitas de textos inéditos, 1], Barcelona,1983, pp. 9-72.

${ }^{57}$ Carlos Barros GuimeránS, ¡Viva el-rey! Ensaios medievais, Vigo, 1996, pp. 187-216.

${ }^{58}$ Ottavio di CAMILI.O, ¿Existe una literatura de oposición en la España de fines de la Edad Media?, "Genèse médiévale de l'Espagne moderne. Du réfus à la révolte: les résistances", edic. de A. Rucquoi, Niza, 1991, pp. 145-170.

s9 José Antonio MARAVALL, La corriente democrática medieval en España y la fórmula 'quod omnes tangit', "Estudios de historia del pensamiento español", I, Madrid, 1973, 173-190.

${ }^{60}$ Jesús Luis CASTILlo Vegas, Política y clases medias. El siglo XV y el maestro salmantino Fernando de Roa, Valladolid, 1987. En su perspectiva democratizadora de la vida política, Fernando de Roa, sin poner en tela de juicio la validez de la institución monárquica, llegará a proponer la conveniencia de la elección del rey frente a la tradicional sucesión hereditaria, defendiendo a toda costa el protagonismo político de las clases medias. 
tales como eran el de communitas o el de bien común ${ }^{61}$. Si tal tipo de enfoques suele hacerse desde la perspectiva de teóricos que forman parte de las élites intelectuales procedentes del mundo universitario, no hay que menospreciar la crítica política canalizada a través de textos poéticos, en donde la definición de un modelo político ocupa un lugar muy secundario, o incluso está ausente, frente al objetivo de desprestigar al titular de la corona 0 algunos de sus colaboradores más señalados ${ }^{62}$.

\section{LA IMAGEN CEREMONIAL}

Frente a los indicios de contestación política que caracterizan a la monarquía castellana, a partir, sobre todo, del comienzo del reinado de Juan I, se observa en Castilla una paulatina tendencia a la mayor presencia de lo ceremonial en las relaciones que la monarquía establece con el conjunto del reino y con los representantes más señalados de la sociedad política. De este modo, puede afirmarse que se produce un proceso de evolución que nos lleva de lo que frecuentemente había sido una especie de "rey oculto", a otro modelo de comportamiento regio en el que el monarca aprovecha momentos políticamente significativos para exhibirse mediante un conjunto de procedimientos ceremoniales que contribuyan a exaltar su posición soberana. Tal cambio, evidentemente, no sucede por casualidad, sino más bien como consecuencia de la necesidad que la propia monarquía tiene de provocar consenso en torno a unas pretensiones más autoritarias y no exentas de contestación, o de restaurar ocasionalmente una imagen de autoridad ensombrecida por acontecimientos recientes. De este modo, estas manifestaciones ceremoniales, mediante las que se produce la exhibición regia, nos sitúan ante todo un síntoma de lo que están siendo transformaciones

${ }^{61}$ Sobre el concepto de communitas: Julio Antonio PARDOS, Communitas, persona invisibilis, "Arqueologia do Estado. Jornadas sobre formas de organizaçao e exerciçio dos poderes do Europa do sul", Lisboa, 1988, pp. 935-965. Sobre las comunidades, pero no ya desde su perspectiva conceptual, sino como fórmula de movilización político-social: Juan Ignacio GUTIÉRREZ NiETO, Semántica del término 'comunidad' antes de 1520: las asociaciones juramentadas de defensa, "Hispania", 136 (1977), pp. 319-367.

${ }^{62}$ Kenneth R. SCHOLBERG, Sátira e invectiva en la España medieval, Madrid, 1971. 
significativas en la relación entre rey y reino, tratándose por ello de fenónemos políticamente relevantes ${ }^{63}$.

El análisis de conjunto de lo que fueron las principales manifestaciones ceremoniales constatables para la realeza trastámara en Castilla permite establecer una amplia tipología de las mismas, mediante la que quedan reflejados los actos políticamente más notables desde la perspectiva del ejercicio del poder real. El análisis interrelacionado de esas ceremonias, desde la óptica de las formas de propaganda y legitimación, apunta hacia una relación de complementariedad entre unas ceremonias y otras en orden a ofrecer una imagen completa de la función gubernativa ejercida por el monarca ${ }^{64}$. Por otra parte, desde el punto de vista escenográfico de lo que es el contenido de determinadas ceremonias, es inevitable la puesta en relación de algunas de las principales manifestaciones ceremoniales con lo que era la mecánica teatral conocida en la época ${ }^{65}$.

Una de las funciones más importantes de las ceremonias políticas que se produce en torno a la realeza fue reducir a una representación civilizada lo que, en muchos aspectos, era una relación de competencia y de confrontación entre intereses contrapuestos. Esto no evitaba totalmente, sin embargo, el que ocasionalmente se produjeran lo que se ha dado en llamar ritos de violencia, mediante los que se exteriorizaba sin reservas la aversión popular hacia un determinado poder particularmente opresivo ${ }^{66}$.

Junto a los análisis de conjunto a que antes se hacía referencia, ha habido algunas ceremonias reales que han sido objeto de especial análisis monográfico. Es, sobre todo, el caso de las entradas reales, manifestación ceremonial particularmente destacada en el caso de la dinastía trastámara, con la que alcanza pleno desarrollo como forma de expresión ritualizada de la soberanía regia y para las que las crónicas, a veces, ofrecen descripciones

\footnotetext{
${ }^{63}$ José Manuel NIETO SORIA, Del rey oculto al rey exhibido: un sintoma de las transformaciones políticas en la Castilla bajomedieval, "Medievalismo. Boletín de la Sociedad Española de Estudios Medievales", 2 (1992), pp. 6-27.

${ }^{64}$ José Manuel NIETO SORIA, Ceremonias de la realeza. ^Propaganda y legitimación en la Castilla Trastámara, Madrid, 1993.

${ }^{65}$ Así lo ha observado, para el caso de la "farsa de Avila", Angus MACKAY, Ritual and Propaganda in Fifteenth-Century Castile, "Past and Present", 107 (1985), pp. 3-43 y, desde una perspectiva más general, Angel GÓMEZ MORENO, El teatro castellano medieval en su marco románico, Madrid, 1991.

${ }^{66}$ Angus MACKAY y Geraldine MACKENDRICK, La semiologia y los ritos de violencia: sociedad y poder en la Corona de Castilla, "En la España Medieval", 11 (1988), pp.125-153.
} 
muy pormenorizadas ${ }^{67}$. Algunas bodas reales también han sido objeto de análisis específico, tales como las de Valladolid, de mayo de 1428, con amplia representación de las realezas castellana y navarra ${ }^{68}$. Los funerales regios han sido objeto de estudio a partir de las descripciones cronísticas ${ }^{69}$, así como desde la perspectiva interpretativa, en cuanto que ceremonia políticamente significativa ${ }^{70}$, pudiéndose establecer los evidentes contrastes entre las tradiciones funerarias trastamaristas y las que se fueron imponiendo ya en el trascurso del siglo XVI y de las centurias siguientes ${ }^{71}$. La fuerte presencia de la mentalidad caballeresca, que tan notable plasmación alcanza en alguna de las principales crónicas nobiliarias del siglo $\mathrm{XV}$, también afectará al ceremonial regio, no faltando ceremonias reales de rasgos típicamente caballerescos ${ }^{72}$. En cambio, actos de gran relieve político como fueron los juramentos ${ }^{73}$, tanto los realizados por el propio monarca ${ }^{74} \mathrm{o}$ efectuados como manifestación de sumisión al mismo, están necesidados de investigaciones monográficas tendentes a establecer un marco interpretativo.

${ }^{67}$ Rosana de ANDRÉs DÍAZ, Las 'entradas reales' castellanas en los siglos XIV y XV, según las crónicas de la época, "En la España Medieval", 4 (1984), pp. 48-62 y, de la misma autora, Fiestas y espectáculos en las 'Relaciones Góticas' del siglo XVI, "En la España Medieval", 14 (1991), pp. 306-336.

${ }^{68}$ Teófilo F. RuIZ, Fiestas, torneos y símbolos de la realeza en la Castilla del siglo XV. Las fiestas de Valladolid de 1428", "Realidad e imágenes del poder. España a fines de la Edad Media", edic. de A. Rucquoi, Valladolid, 1988, pp. 249-265. Otra versión de este mismo trabajo en "Annales. Economies. Sociétés. Civilisations", 46 (1991), pp. 521-546.

${ }^{69}$ Denis MENJOT, Les funérailles des souverains castillans du Bas Moyen Âge racontées par les chroniqueurs: une image de la souveraineté, "Mélanges Jean Larmat. Annales de la Faculté des Lettres et Sciences Humaines de Nice", 39 (1983), pp. 195-209 y, aunque para el periodo anterior a la época trastámara, Emilio MITRE FERNÁNDEZ, La muerte del rey: la historiografía hispánica (1200-1348) y la muerte entre las élites, "En la España Medieval", 11 (1988), pp. 167-184.

${ }^{70}$ Denis MENJOT, Un chrétien qui meurt toujours. Les funérailles royales en Castille à la fin du Moyen Âge. "La idea y el sentimiento de la muerte en la historia y en el arte de la Edad Media", edic. de M. Núñez y E. Portela, Santiago de Compostela, 1987, pp. 27-138 y José Luis MARTín RODRÍGUeZ, El rey ha muerto ;Viva el rey!, "Hispania", 177 (1991), pp. 5-39.

7 Javier VARELA, La muerte del rey. El ceremonial funerario de la monarquia española (1500-1885), Madrid, 1990.

${ }^{72}$ Rosana de ANDRÉs Df́AZ, Las fiestas de caballeria en la Castilla de los Trastámara, "En la España Medieval", 6 (1986), pp. 81-108.

${ }^{73}$ Para este tema es una obra de referencia obligada el libro de Paolo PRODI, Il sacramento del potere. Il giuramento politico nella storia costituzionale dell'Occidente, Bolonia, 1992.

${ }^{74}$ Véase a modo de ejemplo el caso navarro estudiado por José María LACARRA, El juramento de los reyes de Navarra, Madrid, 1972. 
La aproximación a las ceremonias reales debe estar necesariamente relacionada con el enriquecimiento experimentado por la "cortesía", por las formas de etiqueta, en definitiva, que tuvo su plasmación tanto en el marco específico de la corte real, como de las cortes nobiliarias. Son éstas líneas de trabajo en las que queda mucho por hacer. Mientras que algunos textos cronísticos han sido objeto de investigación desde la perspectiva de la etiqueta nobiliaria ${ }^{75}$, otros de tipo legislativo, como Las Siete Partidas, o de índole bien distinta, como el Libro de la Cámara Real del Príncipe Don Juan e offiçios de su casa e serviçio ordinario, de Gonzalo Fernández de Oviedo, han sido utilizados como base fundamental en algún caso para establecer algunos de los rasgos predominantes de la etiqueta propia de la corte real castellana ${ }^{76}$.

Un tipo de fuente que ha sido objeto de un manejo muy limitado hasta el momento con relación a las ceremonias reales son las cuentas reales. Temas relevantes dentro de la actividad ceremonial como son los que afectan al vestuario ${ }^{77}$, a los regalos o a los gastos suntuarios de toda índole, que tanta presencia tienen en los actos ceremoniales, podrían conocerse con mucho más detalle seguramente a partir de tal tipo de información. Del mismo modo, investigaciones basadas en documentación, sobre todo de origen municipal, referidas a la celebración de ceremonias locales conmemorativas de acontecimientos políticos podrían contribuir a dar un perspectiva nueva. Este enfoque ya fue, de hecho, objeto de exploración ocasional hace varias décadas ${ }^{78}$, produciendo algunos resultados muy valiosos, pero habiendo quedado, sin embargo, en la actualidad en un cierto abandono.

Por último, para los años finales del periodo aquí considerado, un problema que conviene dilucidar es el de la sustitución de modelos

${ }^{75}$ Lucien CLARE, Fêtes, jeux et divertissements à la cour du connétable de Castille, Miguel Lucas de Iranzo (1460-1470), "La fête et l'écriture. Thêatre de Cour, Cour-Thêatre en Espagne et en Italie, 1450-1530", Aix-en-Provence, 1987, pp. 5-32.

${ }^{76}$ Jeanne ALLARD, La naissance de l'étiquette: les règles de vie à la cour de Castille à la fin du Moyen Âge, "El discurso político en la Edad Media", edic. de A. Rucquoi, Buenos Aires, 1995, pp. 11-28.

${ }^{77}$ María MARTínez MARTínez, La imagen del rey a través de la indumentaria: el ejemplo de Juan I de Castilla, "Bulletin Hispanique", 96 (1994), pp. 277-287.

${ }^{78}$ José Gestoso Pérez, Los Reyes Católicos en Sevilla (1477-1478), Sevilla, 1891; Manuel FORONDA Y AGUILERA, Honras por Enrique IV y proclamación de Isabel la Católica en la ciudad de Avila, "Boletín de la Real Academia de la Historia", LXIII (1913), pp. 427-434 y Juan de Mata CARRIAzo, Alegrías que hizo Sevilla por la toma de Granada, "Clavileño", 21 (1953), pp. 21-27. 
ceremoniales y de etiqueta cortesana que formaban parte de las tradiciones castellanas por otros de origen extranjero, a lo que parece, según las investigaciones hasta ahora llevadas a cabo, de procedencia predominantemente borgoñona, que se van a ir introduciendo con gran rapidez a partir de la llegada de los cortesanos que acompañaron a Felipe el Hermoso ${ }^{79}$.

\section{LOS SÍMBOLOS DE LA REALEZA}

Los símbolos políticos puestos en juego por la realeza trastámara como medio de propaganda distan en la actualidad todavía mucho de haber sido objeto del análisis que seguramente merecen en el contexto de lo que fueron los distintos recursos propagandísticos empleados. Inevitablemente, su interpretación suele provocar más problemas que las expresiones de carácter retórico-conceptual, ceremonial o incluso iconográfico, en tanto que, por lo general, hay una alusión a ellos menos precisa, menos directa, quedando ésta habitualmente limitada a constatar su presencia, sin que, a buen seguro, en no pocos casos, ni siquiera se produzca tal constatación, en tanto que, el que ésta se efectúe, suele ser consecuencia no sólo del conocimiento que el narrador tenga del significado político específico que posea el símbolo en cuestión, sino de la valoración literaria o política que éste haga de la conveniencia o no de señalar tal significado en el contexto de su exposición.

Tras la importante aportación de Schramm a la descripción de un cierto número de objetos simbólicos empleados en la España medieval ${ }^{80}$, se ha llamado la atención sobre el significado, en tanto que forma de representación simbólica, que algunos objetos poseyeron como expresión de la posición soberana del monarca, tal como ha sucedido, en particular, con la espada ${ }^{81}$.

\footnotetext{
${ }^{79}$ Sobre esta cuestión de la sustitución de las formas rituales y de etiqueta, puede verse: Rafael Domínguez CASAS, Arte y etiqueta de los Reyes Católicos. Artistas, residencias, jardines y bosques, Madrid, 1993, pp. 547-653. 1960

${ }^{80}$ Percy E. SChramm, Las insginias de la realeza en la Edad Media española, Madrid,

${ }^{81}$ Bonifacio Palacios Martín, Los simbolos de la soberanía en la Edad Media española. El simbolismo de la espada, "VII Centenario del Infante don Fernando de la Cerda", Ciudad Real, 1976, pp. 273-296.
} 
Suele ser en las descripciones de manifestaciones ceremoniales donde cabe hallar un volumen de referencias particularmente importante a los símbolos de valor político a los que se les da alguna función específica en ese contexto ceremonial. Desde este punto de vista, cabe comprobar la presencia de lo que serían los símbolos clásicos de la realeza, aunque en proporción muy desigual, coronas, cetros, espadas, tronos, escudos, armas reales, junto a ellos, no suelen faltar los pendones, palios y cruces $^{82}$. Por lo general, el uso ceremonial de la corona será muy reducido, a pesar de su valoración conceptual ${ }^{83}$, pero que, habitualmente, remite a significados distintos de lo que generalmente representa la corona en tanto que objeto simbólico. Junto a las descripciones ceremoniales, no se pueden ignorar diversos soportes de plasmación simbólico-política de carácter iconográfico. Desde este punto de vista, las manifestaciones específicamente artísticas ofrecen mayores dificultades interpretativas, como consecuencia de lo que pueden considerarse como formas figurativas estereotipadas. Más fiables, en cambio, pueden resultar los que son símbolos políticos en sí mismos, con imprescindible contenido iconográfico sobre los que se plasman, a la vez, representaciones simbólicas del poder regio, tal como sucede, por ejemplo, con las monedas ${ }^{84}$, o con los sellos reales, aunque, de nuevo, también en este caso los estereotipos sean inevitables ${ }^{85}$.

Por otra parte, el problema de la conservación y atesoramiento de objetos susceptibles de utilización simbólico-política representa un cuestión

82 José Manuel NiETO SORIA, Ceremonias de la realeza, pp. 183-199.

${ }^{83}$ Sobre la corona como concepto y símbolo político: Manuel GarCía PELAYo, La corona (estudio sobre un símbolo y un concepto político), "Cuadernos Hispanoamericanos", LXX (1967), pp. 11-48.

${ }^{84}$ Fernando CASTILLO CÁCERES, Los símbolos del poder real en las monedas de Pedro I de Castilla, "VII Congreso de Numismática", Madrid, 1991, pp. 501-516 y, del mismo autor, Aproximación a las monedas del príncipe Alfonso de Castilla (1465-1468), "VIII Congreso Nacional de Numismática", Madrid, 1994, pp. 359-371.

${ }^{85}$ Teófilo F. Ruiz, L'image du pouvoir à travers les sceaux de la monarchie castillane, "Génesis medieval del Estado moderno. Castilla y Navarra (1250-1370)", edic. de A. Rucquoi, Valladolid, 1987, pp. 217-228. 
que, sin carecer de base documental ${ }^{86}$, está hoy, en gran medida, por abordar $^{87}$.

\section{LA EXPRESIÓN ARTÍSTICA \\ Y LOS ESCENARIOS DE LA MONARQUÍA}

Del mismo modo que señalaba páginas atrás cómo a fines de la Edad Media se advierte una evidente tendencia a una utilización más amplia de los recursos ceremoniales como medio de propaganda monárquica, otro tanto cabe afirmar con relación a la creación artística promovida desde la realeza ${ }^{88}$. Al igual que, en el caso de Portugal, la época de Manuel I ha sido estudiada desde la perspectiva de la creación de todo un lenguaje político-propagandístico desarrollado a partir de una multiplicidad de recursos iconográficos ${ }^{89}$, la época de los Reyes Católicos representa para la Monarquía Hispánica un impulso extraordinario en ese mismo sentido.

El planteamiento del estudio de la producción artística de la época de los Reyes Católicos, desde la perspectiva de su carácter instrumental al servicio de unos objetivos de prestigio y publicidad, tal como se ha hecho recientemente en algún caso ${ }^{90}$, ha supuesto un importante acercamiento a lo que son los objetivos políticos -en el más amplio sentido del término- de los promotores de esas obras artísticas, lo que permite la valoración de determinadas manifestaciones de la creación artística, en tanto que expresiones de unas pretensiones propagandísticas.

Desde los mismos comienzos de la época trastámara, los monarcas castellanos demostraron particular atención a la construcción de panteones

\footnotetext{
${ }^{86}$ Veáse, por ejemplo, José FERRANDIS TORRES, Datos documentales para la historia del arte español, III, Madrid, 1948, pp. 69-169, a lo que habrá que añadir, a buen seguro, otras fuentes inéditas.

${ }^{87}$ Algunas pistas al respecto pueden hallarse en: Miguel MORÁN y Fernando CHECA, El coleccionismo en España, Madrid, 1985.

${ }^{88}$ Manifestación de ello en Fernando CheCa CREmades y Rosario DíEz del Corral CARnica, Reyes y mecenas. Los Reyes Católicos, Maximiliano l y los inicios de la Casa de Austria en España, Toledo, 1992.

${ }^{89}$ A.M ALVES, Iconologia do poder real no periodo manuelino. A procura de uma linguagem perdida, Lisboa, 1985.

90 Joaquín YARZA LuACES, Los Reyes Católicos. Paisaje artístico de una monarquia, Madrid, 1993.
} 
reales que se constituyeran en señas de identidad de la dinastía y, en difinitiva, de símbolos permanentes del prestigio de una dinastía. Buen ejemplo de ello lo fue la capilla toledana de los Reyes Nuevos, que venía a significar esa apariencia de continuidad con respecto a reinados precedentes que tanto precisaba la nueva dinastía para evitar cualquier imagen de ruptura con el pasado" ${ }^{41}$. Al panteón de Reyes Nuevos le seguirían otros que nos llevarían desde el panteón real de Juan II en la Cartuja de Miraflores ${ }^{92}$, hasta la propia Capilla Real de Granada $^{93}$, que bien pueden ofrecer posibilidades de análisis iconográfico en función de la emisión de una cierta imagen del poder regio.

El palacio o la residencia real debe representar otra referencia obligada desde el punto de vista de la creación de una imagen artística de la realeza y de sus necesidades propagandísticas ${ }^{94}$. El reinado de los Reyes Católicos supuso una época en que se prestó gran atención hacia el palacio real y lo que éste significaba como imagen del poder real y marco natural para la puesta en escena de la etiqueta cortesana, debiendo, no obstante, distinguirse entre lo que eran los palacios reales y reales alcázares, con función definidamente política, y las residencias regias ocasionales, entre las que abundaban los monasterios y los palacios y fortalezas de la nobleza ${ }^{95}$. Un estudio reciente sobre el palacio de los Reyes Católicos en la Aljafería de Zaragoza pone de manifiesto algunas de las posibilidades que tal cuestión ofrece desde la perspectiva aquí considerada ${ }^{\%}$, si bien, para el caso castellano, la pérdida, en su día, del alcázar de Segovia, y su desafortunada restauración, priva del aprovechamiento en todas sus posibilidades de un ejemplo particularmente relevante de residencia real trastamarista.

Dentro de las distintas expresiones artísticas, probablemente, ninguna acaba ofreciendo una imagen tan precisa de la imagen regia, en tanto que

\footnotetext{
91 María Teresa PÉREZ Higuera, Los sepulcros de Reyes Nuevos (catedral de Toledo), "Tekné". 1 (1985), pp. 131-139.

${ }^{22}$ María Jesús GÓMEZ BÁRCENA, Escultura gótica funeraria en Burgos, Burgos, 1988.

${ }^{93}$ A. Gallego Burín, La Capilla Real de Granada, Madrid, 1952.

${ }^{94}$ Un elenco de algunos de los principales palacios y residencias reales de los Trastámara en Castilla en María Teresa PÉrez Higuera, Arquitectura mudéjar en Castilla y León, Valladolid, 1993, pp. 80-120.

${ }^{95}$ Sobre las residencias reales de los Reyes Católicos: Rafael DomínguEz CASAS, Arte y etiqueta de los Reyes Católicos. Artistas, residencias, jardines y bosques, Madrid, 1993.

${ }^{96}$ Gonzalo Borrás Gualis, El palacio de los Reyes Católicos en la Aljafería de Zaragoza, "Fernando II de Aragón, el Rey Católico", Zaragoza, 1996, pp. 363-378.
} 
símbolo político, como la propia representación figurativa de la persona del monarca. Seguramente, ningún monarca trastámara ha sido tan profusamente estudiado desde el punto de vista que ofrece su iconografía como Isabel $\mathbf{I}^{97}$ y Fernando el Católico ${ }^{98}$. Precisamente a partir de la iconografía de este último se ha establecido una tipología iconográfica que, acaso, pueda ser extrapolable a otros monarcas trastámaras, distinguiéndose las siguientes formas representativas ${ }^{49}$ : imagen entronizada, imágenes ecuestres, héroe a la antigua, imagen funeraria. A ellas se deben añadir algunas otras observables en los retratos reales, tanto individuales como familiares, con los reyes como donantes o en la actitud orante, tan extendida durante esta época, sin olvidar la utilización de signos heráldicos y divisas como sustitución de la representación personal del monarca. De entre todas ellas, ninguna ofrecía una imagen tan definidamente regia como la del rey entronizado, de la que el alcázar de Segovia ofrecería, en su día, buen ejemplo para los distintos monarcas trastámara por iniciativa de Enrique IV ${ }^{100}$; del mismo modo que, en lo que se refiere a iluminaciones de manuscritos, el Libro de los Castigos e Documentos del rey don Sancho, ilustrado hacia 1420, supone también un buen panorama de la reiterativa representación de la figura del rey entronizado en diversos momentos en la ejecución de su ministerio real ${ }^{101}$.

El estudio de algunas formas de iconografía figurativa real ha dejado planteado el problema de la similitud entre la representación regia y la nobiliaria ${ }^{102}$, al observarse, sobre todo en el caso de la iconografía funeraria $^{103}$, la presencia de modelos equiparables. Sin ignorar, ciertamente, la semejanza entre determinadas representaciones reales y otras nobiliarias, el llegar a una equiparación entre ambas sólo puede ser resultado de prescindir

97 E. Bermejo, Retratos de Isabel la Católica, "Reales Sitios", 110 (1991), pp. 45-56.

${ }^{98}$ E. Pardo Canalís, Iconografía de Fernando el Católico, Zaragoza, 1962.

${ }^{99}$ Carmen MorTe García, La iconografía real, "Fernando II de Aragón, el Rey Católico", edic. de Esteban Sarasa, Zaragoza, 1996, pp. 143-182.

${ }^{100}$ F. Collar, En torno al Libro de los Retratos de los Reyes de Hernando de Avila, "Boletín del Museo del Prado", 10 (1983), pp. 5 y sigs. y José María AvRIAL Y FLoRES, Segovia pintoresca y el alcázar de Segovia, Segovia, 1953, pp. 98-111.

101 Sobre las iluminaciones del citado manuscrito: J. E. Keller y R. P. KinKade, Iconography in Medieval Spanish Literature, Lexington, 1983.

102 Joaquín YARZA LUACES, La imagen del rey y la imagen del noble en el siglo XV castellano, "Realidad e imágenes del poder en el siglo XV castellano", pp. 267-291.

${ }^{103}$ Manuel NúÑEZ, La indumentaria como símbolo en la iconografía funeraria, "Fragmentos", 10 (1987), pp. 72-84. 
de la enorme variedad de la iconografía real, que no parece del todo parangonable con la nobiliaria, a pesar de la evidente voluntad de emulación por parte de esta última.

A todo ello, habría que añadir la presencia de lo que podría entenderse como la iconografía efímera, creada para un momento concreto, habitualmente destinada a crear espacios ficticios, por lo general, con motivo de entradas reales y de celebraciones político-festivas. Si de tiempos de Juan II se conoce algún caso especialmente notable ${ }^{104}$, ya durante la época de los Reyes Católicos se alcanzó una particular grandilocuencia en este tipo de manifestaciones ${ }^{105}$.

\section{LOS AGENTES DE LA PROPAGANDA POLÍTICA}

El enfoque predominante desde el que se suele abordar el problema de la propaganda política en torno al poder regio suele dar preferencia a la consideración del procedimiento empleado y del contenido propagandístico específico, quedando un tanto pospuesta la valoración de los que podrían entenderse como propagandistas típicos. No obstante, es posible constatar la presencia de tales propagandistas, tanto individuales, como, en algún caso, institucionales, que constituyen, en definitiva, elementos esenciales del propio proceso propagandístico.

Naturalmente, es imprescindible referirse al papel de los cronistas, cuyas obras se convierten, sobre todo en el trascurso del siglo $\mathrm{XV}$, en verdaderos elencos de tópicos útiles para promover actitudes de adhesión o de rechazo hacia una determinada pretensión ${ }^{106}$. Problemas como la

${ }^{104}$ Ejemplos de ello pueden verse en Teófilo F. Ruiz, Fiestas, torneos y símbolos de la realeza en la Castilla del siglo XV. Las fiestas de Valladolid de 1428, "Realidad e imágenes de poder en España a fines de la Edad Media", pp. 249-266; también en mi Ceremonias de la realeza...

${ }^{105}$ V. LLEÓ, Recibimiento en Sevilla del Rey Fernando el Católico, "Archivo Hispalense", 188 (1978), pp. 9-25 y M. FALOMIR, Entradas triunfales de Fernando el Católico en España, "La visión del mundo clásico en el arte español" [VI Jornadas de Arte. Actas. Consejo Superior de Investigaciones Científicas], Madrid, 1993, pp. 49-55

${ }^{106}$ Para lo que se refiere a los cronistas desde el punto de vista de la propaganda regia, pueden encontrarse puntos de vista útiles en: Robert B. TATE, El cronista real castellano durante el siglo XV, "Homenaje a Pedro Sáinz Rodríguez. Estudios Históricos", III, Madrid, 1986, pp. 659-668; José Luis BERMEJO CABRERO, Orígenes del oficio de cronista real, "Hispania", 145 (1980), pp. 395-409, del mismo autor, Las ideas políticas de Enríquez del Castillo, "Revista de la Universidad de Madrid", 86 (1973), pp. 61-78; Michel García, Obra 
evolución personal, desde el punto de vista de su actitud individual ante el hecho propagandístico de algunos de estos cronistas especialmente destacados, así como el predominio de unas fórmulas de exaltación frente a otras de crítica y las diversas técnicas de manipulación en la descripción e interpretación del pasado y de los hechos directamente vividos, pueden considerarse como elementos especialmente relevantes en lo que se refiere a tal cuestión.

En el entorno cortesano, el grupo de los clérigos al servicio del rey, lo que en otro trabajo definí como los clérigos del rey ${ }^{107}$, suele constituir un núcleo muy activo en las iniciativas de propaganda promonárquica. Esta actividad es, además, referible a las más diversas formas de acción propagandística promonárquica ${ }^{108}$. Desde el punto de vista de la retórica política, resultan muy operativos en los más diversos géneros retóricos utilizables con tal tipo de finalidad: el teológico, el histórico, el pedagógico, el literario, el jurídico. Los símbolos religiosos son susceptibles de ser ampliamente utilizados en el terreno político, del mismo modo que rara es la ceremonia política que no exige de una participación clerical más o menos relevante. Por último, determinadas actitudes devocionales de la realeza pueden ser interpretables, en una cierta parte, desde la perspectiva de la estrategia propagandística ${ }^{109}$.

Desde el punto de vista institucional, esta participación del clero cortesano en la propaganda promonárquica encuentra en la capilla real su principal expresión, tratándose de una institución en buena medida destinada

y personalidad del Canciller Ayala, Madrid, 1982; José Luis MARTín RODRíGUEZ, Defensa y justificación de la dinastía Trastámara. Las crónicas de Pedro López de Ayala, "Espacio, Tiempo y Forma" serie III, Historia Medieval, 3 (1990), pp.157-180; Antonio ANTELO IGLESIAS, Alfonso de Palencia: historiografia y humanismo en la Castilla del siglo XV, "Espacio, Tiempo y Forma", serie III, Historia Medieval, 3 (1990), pp.21-40.

107 José Manuel NIETO SORIA, Les clercs du roi et les origines de l'état moderne en Castille: propagande et légitimation (XIIIème-XVème siècles), "Journal of Medieval History", 18 (1992), pp. 297-318.

${ }^{108}$ Una visión de conjunto sobre la función propagandística de los clérigos del rey en José Manuel NiETo SORIA, Iglesia y génesis del Estado Moderno en Castilla (1369-1480), Madrid, 1994, pp. 183-248.

${ }^{109}$ Miguel Angel LADERO QUESADA, Mecenazgo real y nobiliario en monasterios españoles: los jerónimos (siglos XV y XVI), "Príncipe de Viana", anejo 3 XLVII (1986), pp. 409-439 y José Manuel NIETO SORIA, Franciscanos y franciscanismo en la política y en la corte de la Castilla Trastámara, "Anuario de Estudios Medievales", 20 (1990), pp. 109-131. 
a colaborar en la puesta en escena solemne del monarca ${ }^{110}$, constituyendo, además, las distintas capillas reales, ubicadas en las principales catedrales del reino, marcos óptimos para la escenificación artística o ceremonial de la soberanía real.

Es una peculiaridad del siglo XV el notable relieve que van a alcanzar los que José Antonio Maravall denominó como los hombres de saber ${ }^{\prime \prime}$. Se trata de un grupo muy significativo en cuanto que, junto con lo que serían los grandes humanistas del momento interesados por lo político $^{112}$, se van a detectar durante esta época formulaciones políticas que pueden valorarse desde la perspectiva de la construcción de una alternativa a lo que parecía que eran las tendencias autoritarias predominantes, proponiendo, en ocasiones, opciones políticas de carácter más o menos populista, por lo que, en este caso, hay que destacar, sobre todo, la creación de referencias intelectuales susceptibles de ser utilizadas por la propaganda contramonárquica ${ }^{113}$. A ellos hay que añadir aquellos otros hombres de saber, poseedores de la plena confianza real, dedicados a su servicio político-administrativo, suponiendo en algún caso verdaderas sagas de oficiales regios que se suceden en determinados puestos relevantes como, por ejemplo, el de secretario real ${ }^{114}$.

A los ya señalados, sería necesario añadir otros agentes como fueron los poetas cortesanos y los artistas, cuya eficacia en el papel de propagandistas se evidencia en cierta medida por el mayor relieve que van adquiriendo las formas de mecenazgo literario y artístico. El análisis sistemático de sus vinculaciones con el medio cortesano y su dependencia de la protección regia

\footnotetext{
110 José García Oro, Las constituciones de los Reyes Católicos para la Capilla Real de España, "Biblioteca Pontificii Athenaei Antoniani, 24 (Roma, 1985), pp. 283-326 y José Manuel NIETO SORIA, La Capilla Real castellano-leonesa en el siglo XV: constituciones, nombramientos y quitaciones, "Archivos Leoneses", 85-86 (1989), pp. 7-54.

11 José Antonio MARavall, Los 'hombres de saber' o letrados y la formación de su conciencia estamental, "Estudios de historia del pensamiento español", I, pp. 355-390.

112 Nuria Belloso Martín, Política y humanismo en el siglo XV. El maestro Alfonso de Madrigal, el Tostado, Valladolid, 1989.

113 Jesús Luis Castillo Vegas, Política y clases medias. El siglo XV y el maestro salmantino Fernando de Roa. Valladolid, 1987 y Adeline RUCQUOI, Démocratie ou monarchie. Le discours politique dans l'université castillane au XVe siècle, "El discurso político en la Edad Media", pp. 233-255.

114 Es, por ejemplo, el caso de algunas familias conversas, con miembros con formación universitaria, como, entre otras, la de los Díaz de Toledo, tal como puede verse en María del Pilar RÁBADE OBRADó; Una élite de poder: los judeoconversos en la época de los Reyes Católicos, Madrid, 1993.
} 
representa, en la mayoría de los casos, un tema abierto a la investigación $^{115}$.

En definitiva, a partir de lo expuesto en las páginas precedentes, conviene poner de relieve, para concluir, cómo nos hallamos ante un conjunto de problemas para el que, a pesar de su relativa novedad, para el caso concreto de la Castilla trastámara, se dispone en la actualidad de una cierta base bibliográfica a partir de la que cabe establecer una amplia perspectiva de análisis. Por otra parte, la variedad temática desde la que necesariamente debe plantearse el conjunto de cuestiones enumeradadas como de consideración imprescindible, convierte el estudio de la propaganda en el tránsito del medievo a la modernidad, en un ámbito de investigación particularmente necesitado de enfoques de carácter multidisciplinar.

\section{RÉSUMÉ}

L'étude de la propagande politique est une ligne de recherche detachée dans le cadre des récentes perspectives ouvertes au sein de la nouvelle histoire politique. Dans la Castille trastamare, la propagande de la monarchie a un rôle important pour le développement des conflits politiques. Cet article montre les dernières apports bibliographiques publiées sur le sujet et les perspectives de recherche proposées pour les prochains années.

\section{SUMMARY}

The study of political propaganda is one of the main lines of investigation that have emerged during the last years, as a result of the renewal of the Political History. The royalist propaganda played a very important role relating to the political conflicts of Trastamaran Castile. This paper attemps to display the recent bibliography and the perspectives of investigation in the future.

${ }^{115}$ Un extenso panorama sobre la diversidad de artistas de todo nivel y condición al servicio de los Reyes Católicos puede encontrar en la obra ya mencionada de Rafael DOMínGUEZ CASAS, Arte y etiqueta de los Reyes Católicos Perfiles biográficos de numerosos artistas que trabajaron en España a fines del medievo y durante la época renacentista en Fernando CHECA CREMADES y Rosario DÍEZ DEL CORRAL, Reyes y mecenas, pp. 527-578. 